\title{
LPA Gene Polymorphisms and Gene Expression Associated with Coronary Artery Disease
}

\author{
Zi-Kai Song, ${ }^{1}$ Hong-Yan Cao, ${ }^{1}$ Hai-Di Wu, ${ }^{1}$ Li-Ting Zhou, ${ }^{2}$ and Ling Qin ${ }^{1}$ \\ ${ }^{1}$ Department of Cardiology, The First Hospital of Jilin University, Changchun, China \\ ${ }^{2}$ Department of Occupational and Environmental Health, School of Public Health, Jilin University, Changchun, China \\ Correspondence should be addressed to Ling Qin; 114430963@qq.com
}

Received 23 October 2016; Revised 27 March 2017; Accepted 24 October 2017; Published 31 December 2017

Academic Editor: Klaus Wimmers

Copyright (c) $2017 \mathrm{Zi}$-Kai Song et al. This is an open access article distributed under the Creative Commons Attribution License, which permits unrestricted use, distribution, and reproduction in any medium, provided the original work is properly cited.

\begin{abstract}
The aim of our study was to investigate the influence of $L P A$ gene polymorphisms for CAD risk and Lp(a) in a case-control study of Chinese Han population. In addition, we further analyzed the effect of $L P A$ gene expression on plasma levels of $L p(a)$ and CAD risk. First, five SNPs (rs1367211, rs3127596, rs6415085, rs9347438, and rs9364559) in LPA gene were genotyped using the SEQUENOM Mass-ARRAY system in two groups. Second, we used quantitative real-time PCR to examine the mRNA expression levels of $L P A$ gene in 92 cases and 32 controls. Results showed that the frequency of rs6415085-T allele was significantly higher in case group than that in control group $(P<0.05)$. Haplotypes were not associated with CAD risk $(P>0.05)$. And cases with the TT/TG genotype had significantly higher plasma Lp(a) levels compared with those that have the rs6415085 GG genotype $(P<0.05)$. Additionally, the mRNA expression levels in case group are significantly higher than that in control group $(P<0.05)$. Our study confirmed that rs6415085 was associated with CAD and increased plasma Lp(a) levels. And increased mRNA expression level of LPA gene may be a mechanism in development of CAD.
\end{abstract}

\section{Introduction}

The developing of CAD was associated with many risk factors in many studies $[1,2]$. Among these factors, the lipid level is one of the main CAD risk factors. Therefore, total cholesterol, high-density lipoprotein cholesterol (HDL-C), and several other conventional risk factors are often used to predict the risk for cardiovascular disease (CVD) [3, 4]. In the study by Emerging Risk Factors Collaboration, for individuals without known CVD, the combination of lipoprotein(a), apolipoprotein B and A-I, or lipoprotein-associated phospholipase A2 mass to risk scores containing total cholesterol and HDL-C led to slight improvement in CVD prediction [5]. However, the mechanism of action of lipoprotein(a) $[\operatorname{Lp}(a)]$ in cardiovascular risk and the significance of treatment for $\operatorname{Lp}(a)$ are not clear.

The structure of $\mathrm{Lp}(\mathrm{a})$ is complex. It is a plasma lipoprotein consisting of a cholesterol-rich low-density lipoprotein cholesterol (LDL) particle with one molecule of apolipoprotein B100 and an additional protein, apolipoprotein(a), attached via a disulphide bond [6]. Additionally, the plasma levels of $L p(a)$ are effected by genetic factors. A Genome Wide Association Study (GWAS) studied by R. Clarke showed that LPA gene variants were strongly associated with both an increased plasma levels of $\mathrm{Lp}(\mathrm{a})$ and an increased risk of coronary disease [7].

$L P A$, located on chromosome 6q25-q26, encodes the apolipoprotein(a) component of the $\mathrm{Lp}(\mathrm{a})$ lipoprotein particle. In studies for the association between LPA and CAD risk and plasma Lp(a) levels, rs10455872 and rs3798220 were strongly associated with increased plasma levels of $\operatorname{Lp}(\mathrm{a})$, a reduced copy number in $L P A$ (which determines the number of kringle IV-type 2 repeats), and a small $L p(a)$ lipoprotein size $[7,8]$. However, another three loci (rs3127596, rs6415084, and rs9364559) were also significantly associated with CAD risk, and rs3127596 and rs6415084 were also significantly associated with increased plasma levels of $\mathrm{Lp}(\mathrm{a})$. Therefore, the aim of our study was to investigate a possible association between LPA gene polymorphisms and CAD risk in a casecontrol study of Chinese Han population. In addition, we further analyzed the effect of $L P A$ gene expression on plasma $\mathrm{Lp}(\mathrm{a})$ levels and CAD risk in Chinese Han population. 


\section{Materials and Methods}

2.1. Study Subjects. 92 cases and 32 controls were collected for genetic and mRNA expression level analysis. All subjects were Chinese of Han descent from the First Hospital of Jilin University during February 2013 and March 2014. Diagnosis of CAD was carried independently by at least two welltrained physicians based on the following criteria. All patients were identified with CAD by coronary computed tomographic angiography (SIEMNS Somatom Definition AS + 128 row spiral CT). CAD was defined by $\geq 50 \%$ stenosis in any major coronary artery. Patients with nonatherosclerotic vascular diseases, congenital heart disease, cardiomyopathy, valvular disease, renal or hepatic disease, and cancer were excluded. All control subjects had ECG, chest X-ray, and serum analysis. They were classified as healthy subjects based on their normal physical examination results coupled with the absence of personal or family history and reasons for being suspected CAD.

The presence of cardiovascular risk factors, including diabetes mellitus (fasting blood glucose $\geq 7.0 \mathrm{mmol} / \mathrm{L}$, and/or using glucose-lowering medication, including insulin), hypertension, and cigarette smoking, was obtained from all participants. Hypertension was defined according to seated blood pressure readings of 140/90 $\mathrm{mmHg}$ and higher, and/or subjects' receiving antihypertensive medication. In this study, a smoking habit was defined as a daily intake of $>10$ cigarettes [9].

This study complied with the Declaration of Helsinki. All the subjects have written informed consent for the study, which was approved by ethics committee of Jilin University, Changchun, China.

2.2. Laboratory Examination. Before starting the study, all participants underwent an initial screening assessment that included medical history, vital signs, a 12-lead electrocardiogram, and measurement of lipid variables and novel risk factors. Venous blood was collected in the morning after an overnight (8-12 hours) fast. Serum/plasma samples were frozen and stored at $-80^{\circ} \mathrm{C}$ prior to analysis. All measurements were performed in a central laboratory.

2.3. SNP Selection, Identification, and Genotyping. The candidate single nucleotide polymorphisms (SNPs) (rs3127596 and rs9364559) were selected from a GWAS study. Another three tagging SNPs (rs1367211, rs6415085, and rs9347438) were chosen from genotyped SNPs in Chinese Han population (CHB) of the HapMap project (the Phase I database). All SNPs were restricted to minor allele frequency bigger than 15\% in HAPMAP-CHB database (https://www.hapmap.org). Genomic DNA used for PCR amplification was extracted from the whole blood sample using a DNA extraction kit (Takara, China). Primers of amplification and extension were used by AssayDesigner3.1 software. Amplification and extension primers sequences of five loci in LPA gene were described by us previously [10]. Genotypes were assigned real-time using Typer 4.0 software (Sequenom). As quality controls, $5-10 \%$ of the samples were genotyped in duplicate. No inconsistencies were observed. Controls distributed in each 384-well plate were also consistent. Cluster plots were made of the signals from the low and the high mass allele.

2.4. RNA Isolation and Quantification. High-quality total RNA was isolated from human peripheral blood samples from case and control groups with different genotypes in Chinese Han population, and $500 \mathrm{ng}$ of total RNA was reverse transcribed. LPA mRNAs were quantified by realtime quantitative polymerase chain reaction using the $5^{\prime}$ nuclease assay and the ABI Prism 7300 Sequence Detection System (Applied Biosystems, Foster City, CA). Oligonucleotide primers and TaqMan probes are given: $5^{\prime}$-GGGACAAATAAATGGGCAGGT-3', 5' -AATGAAGAGGATGCACAGAGAGG3'. The relative gene expression levels were calculated by $2^{-\Delta \mathrm{Ct}}\left(\Delta \mathrm{Ct}=\mathrm{Ct}_{\text {target }}-\mathrm{Ct}_{\text {actin }}\right)[11]$.

2.5. Statistical Analysis. Data were expressed as percentages of total for categorical variables, or mean \pm SD. The statistical analyses on the characteristics of the subjects were performed with Pearson $\chi^{2}$ test for the categorical variables such as sex, smokers, drinkers, hypertension, and diabetes and with Student's $t$-test for the continuous variable of age, total cholesterol (TC), triglyceride (TG), LDL-C, and HDL-C with normal distribution. Association between different groups and alleles or genotypes of LPA gene polymorphisms was analyzed using either $\chi^{2}$ or Fisher exact test. Plasma Lp(a) levels and mRNA expression levels of the LPA gene were nonnormal distribution data, which were expressed as $\mathrm{M} \pm \mathrm{Q}$. For the association between SNPs and the mRNA expression level of the LPA gene, rank-sum test was used. SPSS 16.0 was used for above analyses.

\section{Results}

3.1. Characteristics of Participants. The baseline characteristics of case and control groups are shown in Table 1. There was no significant difference of the mean age, sex, rate of drinking, prevalence of diabetes mellitus, body mass index (BMI), serum TG, and TC level between two groups. Compared with control group, case group had more smokers and more individuals with hypertension. Additionally, compared with control group, case group had higher level of serum LDL-C, HDL-C and $\operatorname{Lp}(\mathrm{a})(P<0.05)$.

3.2. Allele and Genotype Analysis. The distributions of alleles and genotypes of five loci among participants were presented in Table 2. Analysis with SPSS 16.0 showed that allele frequencies of rs6415085 were significantly higher in case group than that in control group $(P<0.05)$. But, there was no difference of genotype frequencies for rs6415085 between two groups $(P>0.05)$. Additionally, there were no differences in genotype and allele frequencies for the other four SNPs between two groups $(P>0.05)$.

3.3. Linkage Disequilibrium (LD) Analysis. LD analysis for five SNPs on LPA gene in cases and controls, respectively, results showed that rs1367211 and rs6415085 $\left(D^{\prime}=0.99\right)$, rs1367211 and rs9347438 $\left(D^{\prime}=0.99\right)$, and rs3127596 and rs9364559 $\left(D^{\prime}=0.99\right)$ were in tight LD (Figure 1). Results 
TABLE 1: Base characteristics of case and control group.

\begin{tabular}{|c|c|c|c|}
\hline Variable & Case group $(n=92)$ & Control group $(n=32)$ & $P$ \\
\hline $\operatorname{Age}^{\mathrm{a}}$ (year) & $66.34 \pm 11.83$ & $62.18 \pm 11.07$ & 0.296 \\
\hline $\operatorname{Sex}(\%)$ & 58.7 & 75.0 & 0.100 \\
\hline $\operatorname{BMI}^{\mathrm{a}}\left(\mathrm{kg} / \mathrm{m}^{2}\right)$ & $24.19 \pm 2.68$ & $24.01 \pm 3.31$ & 0.431 \\
\hline Smoking (\%) & 37.5 & 18.1 & 0.021 \\
\hline Drinking (\%) & 20.0 & 19.2 & 0.842 \\
\hline Hypertension (\%) & 49.4 & 28.1 & 0.037 \\
\hline Diabetes mellitus (\%) & 25.8 & 21.9 & 0.656 \\
\hline $\mathrm{TC}^{\mathrm{a}}(\mathrm{mmol} / \mathrm{L})$ & $5.09 \pm 0.88$ & $4.77 \pm 1.07$ & 0.143 \\
\hline $\mathrm{TG}^{\mathrm{a}}(\mathrm{mmol} / \mathrm{L})$ & $2.26 \pm 1.39$ & $1.77 \pm 1.01$ & 0.074 \\
\hline 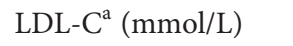 & $3.08 \pm 0.84$ & $2.74 \pm 0.82$ & 0.021 \\
\hline $\mathrm{HDL}^{\mathrm{a}}(\mathrm{mmol} / \mathrm{L})$ & $1.21 \pm 0.32$ & $1.16 \pm 0.24$ & 0.032 \\
\hline $\mathrm{Lp}(\mathrm{a})^{\mathrm{b}}(\mathrm{mmol} / \mathrm{L})$ & $226.34 \pm 123.25$ & $195.96 \pm 117.19$ & 0.000 \\
\hline
\end{tabular}

${ }^{\mathrm{a}}$ Variables are described based on mean $\pm \mathrm{SD} .{ }^{\mathrm{b}}$ Variables are described based on median $\pm \mathrm{QR}$.

TABLE 2: SNPs loci genotype and allelic frequency distribution of LPA gene in two groups.

\begin{tabular}{|c|c|c|c|c|c|c|c|c|c|c|}
\hline \multirow{3}{*}{$\begin{array}{l}\text { SNPs } \\
\text { Rs1367211 }\end{array}$} & \multicolumn{6}{|c|}{ Genotype } & \multicolumn{4}{|c|}{ Allelic } \\
\hline & \multicolumn{3}{|c|}{ Cases (92) } & \multicolumn{3}{|c|}{ Controls (32) } & \multicolumn{2}{|c|}{ Cases (92) } & \multicolumn{2}{|c|}{ Controls (32) } \\
\hline & 2 & 27 & 58 & 3 & 12 & 17 & 31 & 143 & 18 & 46 \\
\hline Rs3127596 & 63 & 22 & 3 & 27 & 4 & 0 & 148 & 28 & 58 & 4 \\
\hline Rs9364559 & 40 & 40 & 12 & 11 & 18 & 2 & 120 & 64 & 40 & 22 \\
\hline Rs6415085 & 54 & 17 & 15 & 23 & 2 & 3 & 125 & $47^{*}$ & 48 & 8 \\
\hline Rs9347438 & 13 & 43 & 31 & 1 & 16 & 14 & 69 & 105 & 18 & 44 \\
\hline
\end{tabular}

${ }^{*} \mathrm{P}<0.05$.

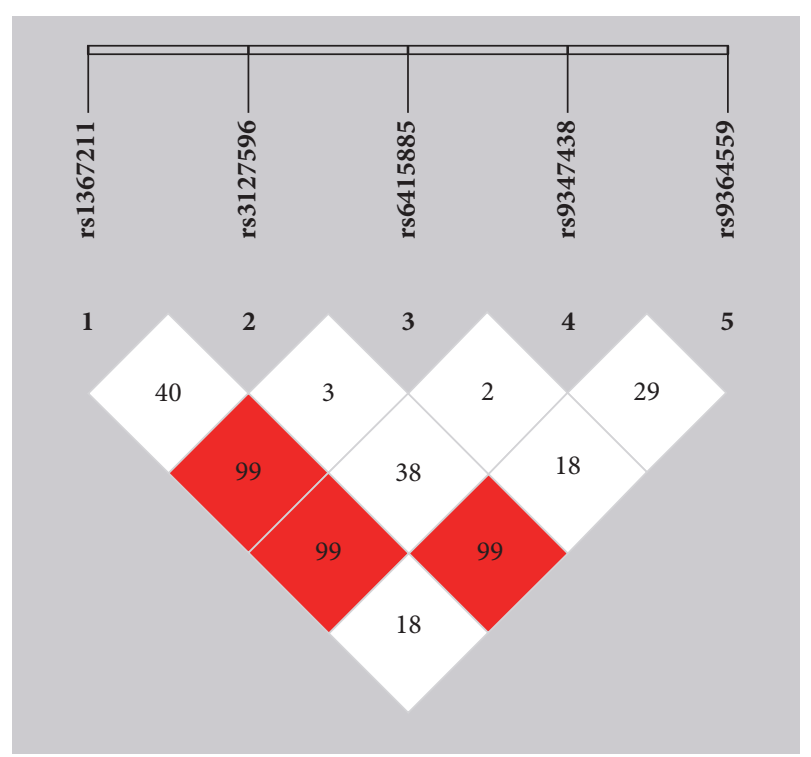

FIGURE 1: Linkage disequilibrium (LD) pattern between the five LPA single nucleotide polymorphisms (SNPs) genotyped in this study. Rs1367211 and rs6415085, rs1367211 and rs9347438, and rs3127596 and $\mathrm{rs} 9364559$ were in tight $\mathrm{LD}\left(D^{\prime}=0.99\right)$ and were organized in a single haplotype block.

of haplotype analysis showed that haplotypes were not associated with CAD risk $(P>0.05)$.
3.4. The Effect of LPA SNPs on Serum LP(a) Levels in Chinese Han Population. Each SNP was tested for an association with $\mathrm{Lp}(\mathrm{a})$ levels. Results from this analysis are presented in Table 3. There were no significant differences in plasma Lp(a) levels between case and control groups with different genotypes $(P>0.05)$. But, we further analyzed the effect of $L P A$ SNPs on serum Lp(a) levels in cases and controls, respectively. Results showed that patients with the TT/TG genotype had significantly higher plasma Lp(a) levels compared with those that have the rs6415085 GG genotype $(P<0.05)$.

3.5. Real-Time RT-PCR Analyses Identified High Expression Level of LPA Gene Related to CAD Risk. Further comparing the mRNA expression levels of LPA gene in two groups (Figure 2), the mRNA expression levels in case group are significantly higher than that in control group $(P<0.05)$.

3.6. Assessment of Association between SNPs and the mRNA Expression Level of LPA Gene. We used quantitative realtime polymerase chain reaction (qRT-PCR) analysis to assess whether SNPs were associated with the expression level of $L P A$ gene. The data showed that there was no significant association between SNPs and the expression level of LPA gene $(P>0.05)$ (Table 4$)$.

3.7. Logistic Regression Analysis. As shown in Table 5, ageing, sex, diabetes mellitus, hypertension, smoking, drinking, TC, TG, LDL-C, HDL-C, Lp(a), mRNA expression level of LPA 
TABLE 3: The association between SNPs and serum $\operatorname{Lp}(\mathrm{a})$ level $(\mathrm{M} \pm \mathrm{Q})$.

\begin{tabular}{|c|c|c|c|c|}
\hline SNPs & Case group & Control group & $\chi^{2}$ & $P$ \\
\hline \multicolumn{5}{|l|}{ rs1367211 } \\
\hline $\mathrm{AA}+\mathrm{AG}$ & $241.00 \pm 75.91$ & $216.24 \pm 97.19$ & \multirow{2}{*}{1.915} & \multirow{2}{*}{0.166} \\
\hline GG & $237.67 \pm 172.35$ & $195.96 \pm 84.54$ & & \\
\hline \multicolumn{5}{|l|}{ rs3127596 } \\
\hline $\mathrm{GG}+\mathrm{GA}$ & $242.23 \pm 104.12$ & $195.42 \pm 87.46$ & \multirow{2}{*}{1.077} & \multirow{2}{*}{0.299} \\
\hline $\mathrm{AA}$ & $218.82 \pm 157.81$ & $171.94 \pm 91.94$ & & \\
\hline \multicolumn{5}{|l|}{ rs9364559 } \\
\hline $\mathrm{GG}+\mathrm{GA}$ & $246.57 \pm 129.56$ & $211.94 \pm 78.15$ & \multirow{2}{*}{0.893} & \multirow{2}{*}{0.345} \\
\hline AA & $258.04 \pm 193.16$ & $202.23 \pm 91.21$ & & \\
\hline \multicolumn{5}{|l|}{ rs6415085 } \\
\hline $\mathrm{TT}+\mathrm{TG}$ & $279.50 \pm 95.04^{*}$ & $218.45 \pm 107.26$ & \multirow{2}{*}{2.234} & \multirow{2}{*}{0.135} \\
\hline GG & $197.56 \pm 99.74$ & $194.24 \pm 81.11$ & & \\
\hline \multicolumn{5}{|l|}{ rs9347438 } \\
\hline $\mathrm{CC}+\mathrm{CT}$ & $226.56 \pm 120.57$ & $188.00 \pm 123.85$ & \multirow{2}{*}{1.568} & \multirow{2}{*}{0.211} \\
\hline $\mathrm{TT}$ & $238.82 \pm 175.95$ & $194.24 \pm 93.28$ & & \\
\hline
\end{tabular}

TABLE 4: The association between SNPs and the mRNA expression level of LPA gene $(\mathrm{M} \pm \mathrm{Q})$.

\begin{tabular}{|c|c|c|c|c|}
\hline SNPs & Case group & Control group & $\chi^{2}$ & $P$ \\
\hline \multicolumn{5}{|l|}{ rs1367211 } \\
\hline $\mathrm{AA}+\mathrm{AG}$ & $4.955 \times 10^{-2} \pm 14.208 \times 10^{-2}$ & $3.874 \times 10^{-2} \pm 6.870 \times 10^{-2}$ & 1.401 & 0.237 \\
\hline \multicolumn{5}{|l|}{ rs3127596 } \\
\hline $\mathrm{GG}+\mathrm{GA}$ & $8.133 \times 10^{-2} \pm 31.607 \times 10^{-2}$ & $5.833 \times 10^{-2} \pm 2.956 \times 10^{-2}$ & 1.293 & 0.256 \\
\hline \multicolumn{5}{|l|}{ rs9364559 } \\
\hline $\mathrm{GG}+\mathrm{GA}$ & $6.629 \times 10^{-2} \pm 28.219 \times 10^{-2}$ & $5.834 \times 10^{-2} \pm 7.659 \times 10^{-2}$ & 0.872 & 0.350 \\
\hline \multicolumn{5}{|l|}{ rs6415085 } \\
\hline $\mathrm{TT}+\mathrm{TG}$ & $4.374 \times 10^{-2} \pm 30.729 \times 10^{-2}$ & $9.554 \times 10^{-2} \pm 40.637 \times 10^{-2}$ & 0.195 & 0.659 \\
\hline \multicolumn{5}{|l|}{ rs9347438 } \\
\hline $\mathrm{CC}+\mathrm{CT}$ & $8.597 \times 10^{-2} \pm 32.258 \times 10^{-2}$ & $5.555 \times 10^{-2} \pm 8.500 \times 10^{-2}$ & 3.622 & 0.057 \\
\hline
\end{tabular}

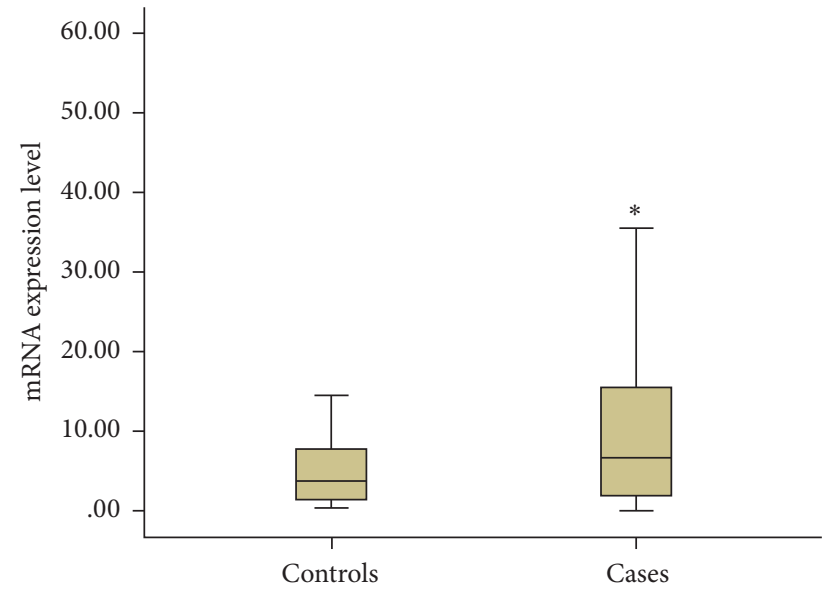

FIgURE 2: The mRNA expression levels of LPA gene in case and control groups $(\mathrm{M} \pm \mathrm{Q}) .{ }^{*}$ after adjustment of the presence of smoking, hypertension by logistic regression analysis, $P<0.05$, compared with controls.

gene, and five SNPs were included in the multivariate logistic regression model. Result showed that LDL-C, smoking,
Lp(a), and high mRNA expression level of LPA gene all increased the risk of CAD. But LDL-C was the most predictive risk factor for CAD.

\section{Discussion}

The pathogenesis of CAD is not clear. But many studies proved that the interaction of genetic and environmental factors is the main factor for the developing of CAD. In addition to environmental factors such as age, gender, bad behavior, poor diet, obesity, dyslipidemia, hypertension, and diabetes, GWAS study has identified several novel susceptibility loci for CAD [12-16]. But many SNPs appear in noncoding regions of the genome. Therefore, the complex mechanisms are still largely unknown. Many studies have confirmed that SNPs which influence mRNA expression are known as expression Quantitative Trait Loci (eQTL) [17-20].

In this study, we observed frequency of $\mathrm{T}$ allele of rs6415085 was increased in individuals with CAD. But there was no difference of genotype frequencies for rs6415085 between two groups. Further results of LD analysis showed that rs1367211 and rs6415085, rs1367211 and rs9347438, and 
TABLE 5: Multivariate logistic regression analysis showing the predictors of CAD.

\begin{tabular}{lcccc}
\hline Risk factor & B & S.E. & Wald & \\
\hline Lp(a) & 0.010 & 0.004 & 7.068 & 0.008 \\
LDL-C & 1.438 & 0.483 & 8.852 & 0.003 \\
Smoking & -1.214 & 0.607 & 3.997 & 0.046 \\
LPA expression level & 0.093 & 0.042 & 4.833 & 0.028 \\
\hline
\end{tabular}

rs3127596 and rs9364559 were in tight LD. But haplotypes were not associated with CAD risk. In addition, patients with the rs6415085 TT/TG genotype had significantly higher Lp(a) levels than that with the rs6415085 GG genotype. Therefore, above result suggests that $L P A$ gene may be the potential mechanism leading to atherosclerosis and associated with an increased level of $\mathrm{Lp}(\mathrm{a})$. Above results are consistent with previous studies [21-23]. Rs10455872 and rs3798220 in LPA gene were proved strongly associated with plasma $\mathrm{Lp}(\mathrm{a})$ levels and CAD and reduce the copy number at LPA (which determines the number of kringle IV-type 2 repeats) and a small Lp(a) lipoprotein size $[7,8]$.

Meanwhile, we found that LPA gene expression was significantly increased in individuals with CAD compared to those without CAD. And CAD patients have higher plasma Lp(a) levels than healthy individuals. Therefore, these results further confirmed the relationship between Lp(a) levels and CAD risk [24-26].

The mechanism research by Niccoli et al. showed that higher plasma $\mathrm{Lp}$ (a) levels exhibited a higher prevalence of lipidic plaque at the site of the culprit stenosis, a wider lipid arc, and a higher prevalence of thin-cap fibroatheroma [27]. Therefore, the role of therapies targeting $\mathrm{Lp}(\mathrm{a})$ can decrease CAD risk through reduction of vulnerable plaque features of patients with CAD. Regression analysis results showed that the plasma $\mathrm{Lp}(\mathrm{a})$ and LDL-C levels are associated with CAD. Combined with above results, we speculate rs6415085 TT/TG genotype may, through increased plasma Lp(a) levels, increase CAD risk.

But our results showed that LPA mRNA expression level is not significantly increased in patients with rs6415085 TT/TG genotype. The above results are mainly due to rs6415085 being intron variant in noncoding regions of $L P A$ gene. In the future through the study of introns and siRNA research it is expected to clear the mechanism of SNP.

A potential limitation of our study was the numbers of subject in our study, which may limit statistical power and generalization to the overall Chinese population. Nevertheless, our results are in accordance with former studies that suggested a putative influence of LPA gene polymorphisms in the mechanisms associated with CAD. In addition, we did not collect data of treatment for hyperlipidemia, which maybe affect the relationship between genotypes and lipid levels. In further study, we should collect more comprehensive data about angiography and history of treatment to analyze association between gene variants, lipid level, and CAD severity.

In conclusion, our study confirmed that $\mathrm{T}$ allele of rs6415085 was associated with CAD and rs6415085 TT/TG genotype which maybe increased plasma $\operatorname{Lp}(\mathrm{a})$ levels. And increased mRNA expression level of LPA gene may be a mechanism in development of CAD. However, further studies encompassing larger number of patients are needed to confirm the results obtained in this study.

\section{Conflicts of Interest}

The authors have declared that no conflicts of interest exist.

\section{Authors' Contributions}

Zi-Kai Song contributed to this work.

\section{Acknowledgments}

The authors thank all participants for their support and participation. Special thanks are due to the support of Hepatology Department, Institute of Translational Medicine, the First Hospital, Jilin University, Changchun, China.

\section{References}

[1] S. M. Grundy, R. Pasternak, P. Greenland, S. J. r. Smith, and V. Fuster, "Assessment of cardiovascular risk by use of multiplerisk-factor assessment equations: a statement for healthcare professionals from the American Heart Association and the American College of Cardiology," Circulation, vol. 100, no. 13, pp. 1481-1492, 1999.

[2] P. Greenland, M. D. Knoll, J. Stamler et al., "Major risk factors as antecedents of fatal and nonfatal coronary heart disease events," The Journal of the American Medical Association, vol. 290, no. 7, pp. 891-897, 2003.

[3] J. Perk, G. De Backer, H. Gohlke et al., "European guidelines on cardiovascular disease prevention in clinical practice (version 2012). The fifth joint task force of the European Society of Cardiology and Other Societies on cardiovascular disease prevention in clinical practice (constituted by representatives of nine societies and by invited experts)," European Heart Journal, vol. 33, no. 13, pp. 1635-701, 2012.

[4] S. Parish, A. Offer, R. Clarke et al., "Heart Protection Study Collaborative G: Lipids and lipoproteins and risk of different vascular events in the MRC/BHF Heart Protection Study," Circulation, vol. 125, no. 20, pp. 2469-2478, 2012.

[5] E. Di Angelantonio, P. Gao, and J. Danesh, "Cardiovascular Disease Risk Prediction Factors-Reply," Journal of the American Medical Association, vol. 308, no. 19, p. 1969, 2012.

[6] J. B. Dubé, M. B. Boffa, R. A. Hegele, and M. L. Koschinsky, "Lipoprotein(a): More interesting than ever after 50 years," Current Opinion in Lipidology, vol. 23, no. 2, pp. 133-140, 2012.

[7] R. Clarke, J. F. Peden, J. C. Hopewell et al., "Genetic variants associated with $\mathrm{Lp}$ (a) lipoprotein level and coronary disease," The New England Journal of Medicine, vol. 361, no. 26, pp. 25182528, 2009. 
[8] Y. Wang, L. Wang, X. Liu et al., "Genetic variants associated with myocardial infarction and the risk factors in Chinese population," PLoS ONE, vol. 9, no. 1, Article ID e86332, 2014.

[9] Y.-H. Chen, J.-M. Liu, R.-J. Hsu et al., "Angiotensin converting enzyme DD genotype is associated with acute coronary syndrome severity and sudden cardiac death in Taiwan: a casecontrol emergency room study," BMC Cardiovascular Disorders, vol. 12, article no. 6, 2012.

[10] Z.-K. Song, H.-D. Wu, H.-Y. Cao, and L. Qin, “The association between the LPA gene polymorphism and coronary artery disease in chinese han population," BioMed Research International, vol. 2014, Article ID 370670, 2014.

[11] K. J. Livak and T. D. Schmittgen, "Analysis of relative gene expression data using real-time quantitative PCR and the 2(Delta Delta C (T))," Methods, vol. 25, no. 4, pp. 402-408, 2001.

[12] P. R. Burton, D. G. Clayton, L. R. Cardon et al., "Genome-wide association study of 14,000 cases of seven common diseases and 3,000 shared controls," Nature, vol. 447, no. 7145, pp. 661-678, 2007.

[13] R. McPherson, A. Pertsemlidis, N. Kavaslar et al., "A common allele on chromosome 9 associated with coronary heart disease," Science, vol. 316, no. 5830, pp. 1488-1491, 2007.

[14] A. Helgadottir, G. Thorleifsson, A. Manolescu et al., "A common variant on chromosome 9p21 affects the risk of myocardial infarction," Science, vol. 316, no. 5830, pp. 1491-1493, 2007.

[15] H. Ding, Y. Xu, X. Wang et al., "9p21 is a Shared Susceptibility Locus Strongly for Coronary Artery Disease and Weakly for Ischemic Stroke in Chinese Han Population," Circulation: Cardiovascular Genetics, vol. 2, no. 4, pp. 338-346, 2009.

[16] N. J. Samani, J. Erdmann, A. S. Hall et al., "Genomewide association analysis of coronary artery disease," The New England Journal of Medicine, vol. 357, no. 5, pp. 443-453, 2007.

[17] D. L. Nicolae, E. Gamazon, W. Zhang, S. Duan, M. Eileen Dolan, and N. J. Cox, "Trait-associated SNPs are more likely to be eQTLs: Annotation to enhance discovery from GWAS," PLoS Genetics, vol. 6, no. 4, Article ID e1000888, 2010.

[18] X. Zhang, A. D. Johnson, A. E. Hendricks et al., "Genetic associations with expression for genes implicated in GWAS studies for atherosclerotic cardiovascular disease and blood phenotypes," Human Molecular Genetics, vol. 23, no. 3, Article ID ddt461, pp. 795-782, 2014.

[19] T. M. Teslovich, K. Musunuru, and A. V. Smith, "Biological, clinical and population relevance of 95 loci for blood lipids," Nature, vol. 466, no. 7307, pp. 707-713, 2010.

[20] C. J. Willer, E. M. Schmidt, S. Sengupta et al., "Discovery and refinement of loci associated with lipid levels," Nature genetics, vol. 45, no. (11), pp. 1274-1283, 2013.

[21] J.-P. Chretien, J. Coresh, Y. Berthier-Schaad et al., "Three singlenucleotide polymorphisms in LPA account for most of the increase in lipoprotein(a) level elevation in African Americans compared with European Americans," Journal of Medical Genetics, vol. 43, no. 12, pp. 917-923, 2006.

[22] M. B. Lanktree, S. S. Anand, S. Yusuf, and R. A. Hegele, "Comprehensive analysis of genomic variation in the LPA locus and its relationship to plasma lipoprotein(a) in south asians, chinese, and european caucasians," Circulation: Cardiovascular Genetics, vol. 3, no. 1, pp. 39-46, 2010.

[23] R. C. Deo, J. G. Wilson, C. Xing et al., "Single-nucleotide polymorphisms in LPA explain most of the Ancestry-specific variation in Lp(a) levels in African Americans," PLoS ONE, vol. 6, no. 1, Article ID e14581, 2011.
[24] B. Mihaylova, J. Emberson, and L. Blackwell, "The effects of lowering LDL cholesterol with statin therapy in people at low risk of vascular disease: meta-analysis of individual data from 27 randomised trials," The Lancet, vol. 380, no. 9841, pp. 581590, 2012.

[25] M. V. Holmes, F. W. Asselbergs, T. M. Palmer et al., "Mendelian randomization of blood lipids for coronary heart disease," European Heart Journal, vol. 36, no. 9, pp. 539-550, 2015.

[26] B. G. Nordestgaard, M. J. Chapman, K. Ray et al., "Lipoprotein(a) as a cardiovascular risk factor: current status," European Heart Journal, vol. 31, no. 23, pp. 2844-2853, 2010.

[27] G. Niccoli, D. Chin, G. Scalone et al., "Data on the lipoprotein (a), coronary atherosclerotic burden and vulnerable plaque phenotype in angiographic obstructive coronary artery disease," Data in Brief, vol. 7, pp. 1409-1412, 2016. 


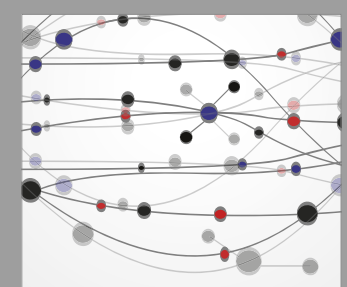

The Scientific World Journal
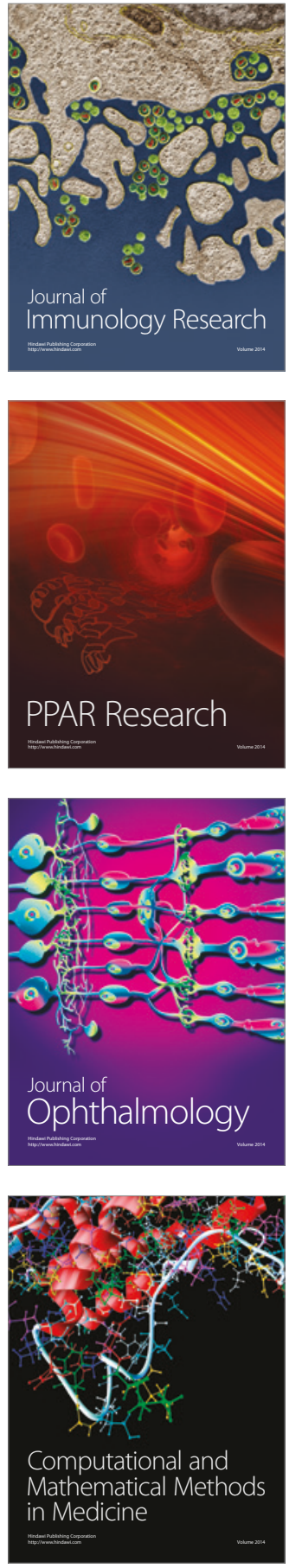

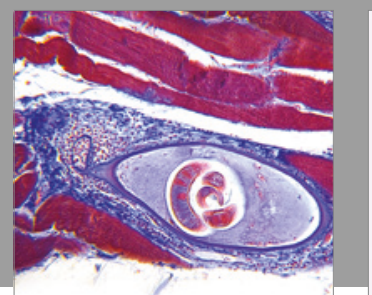

Gastroenterology Research and Practice
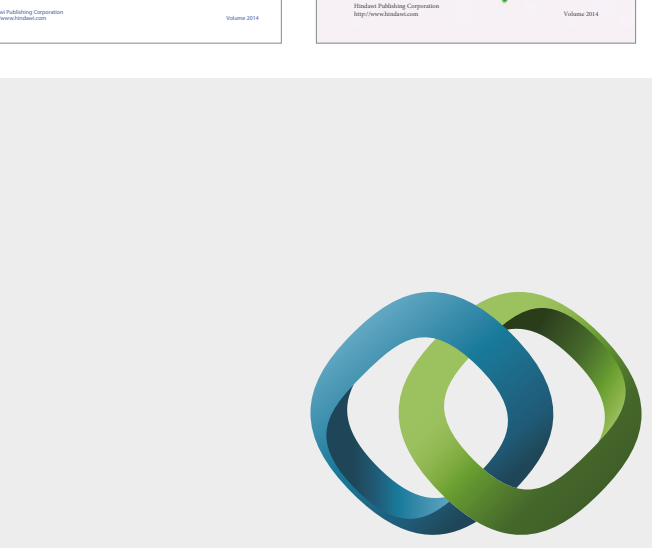

\section{Hindawi}

Submit your manuscripts at

https://www.hindawi.com
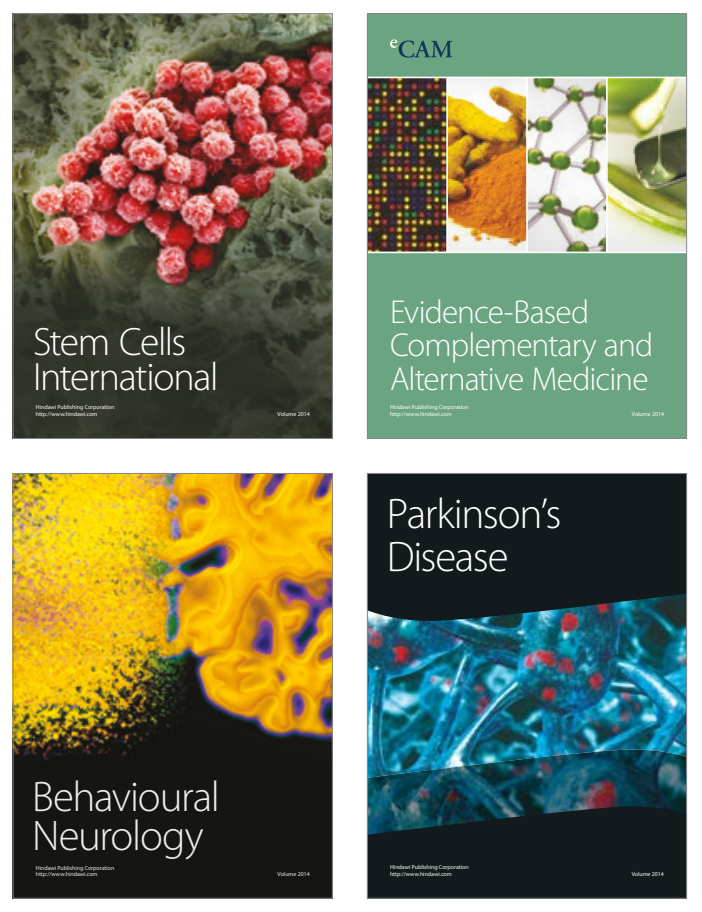
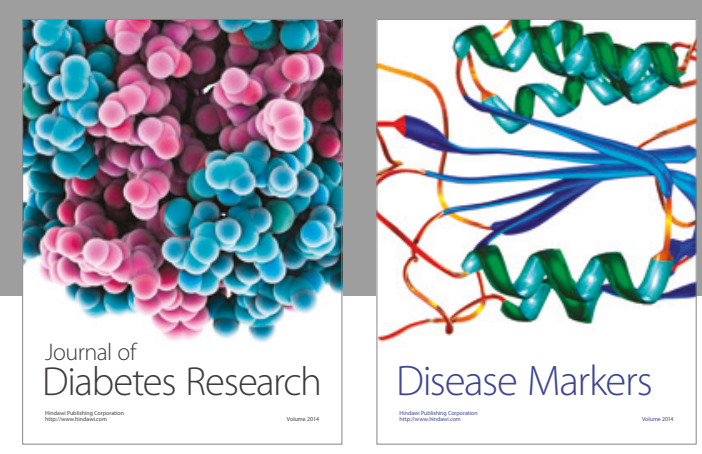

Disease Markers
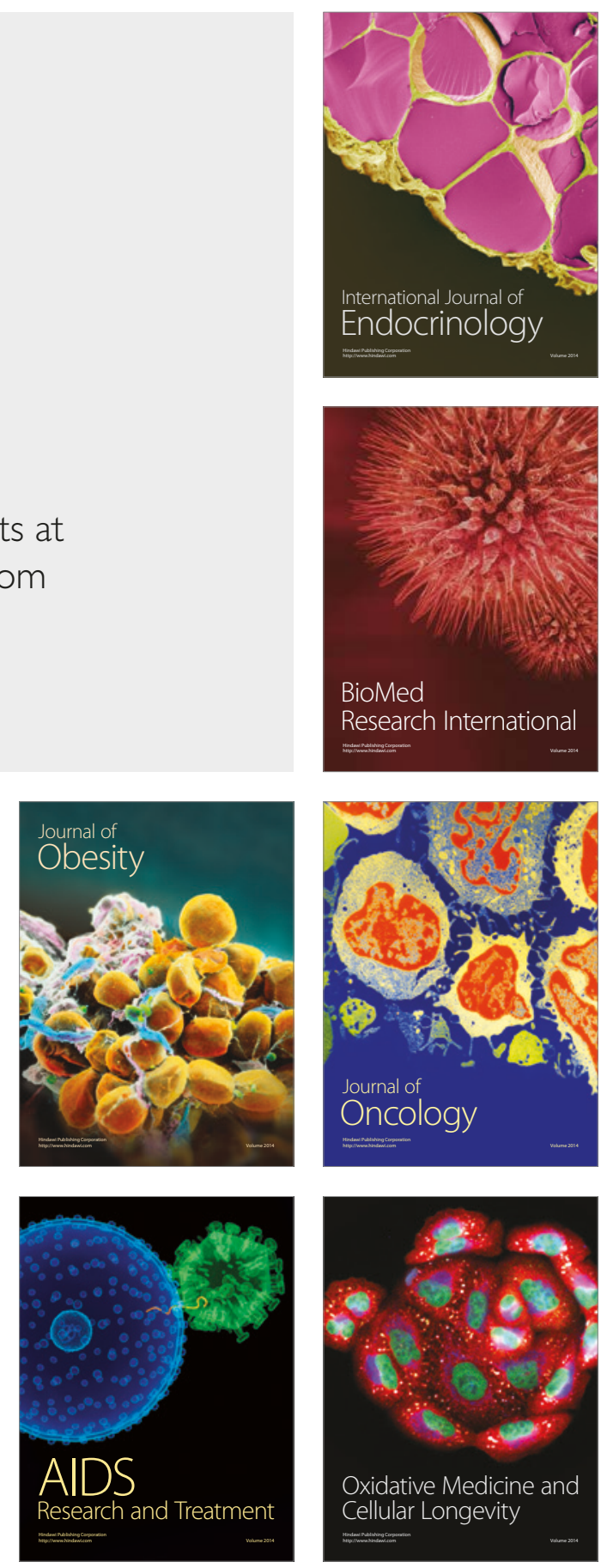